研究

\title{
イオン注入によるアルミナ表面硬度の変化
}

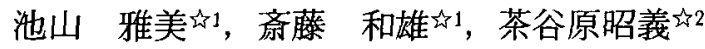

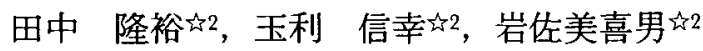 \\ 谷 英治放3 \\ 41 名古屋工業技術研究所, 广462 名古屋市北区平手町1-1. \\ 出2 大阪工業技術研究所， 个563 池田市緑丘1-8-31.

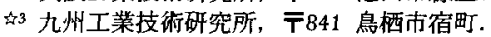

\section{Variations of Surface Hardness of Alumina Induced by Ion Implantation}

\author{
Masami Ikeyama ${ }^{21}$, Kazuo Saitoh ${ }^{2}$, Akiyoshi Chayahara \\ Takahiro Tanaka ${ }^{\natural 2}$, Nobuyuki Tamari ${ }^{\natural 2}$

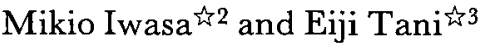 \\ it National Industrial Research Institute of Nagoya, 1-1 Hirate-cho Kita-ku, Nagoya 462. \\ «2 Osaka National Research Institute, AIST, Midorigaoka, Ikeda 563. \\ \&3 Kyushu National Industrial Research Institute, Shuku-machi, Tosu 841.
}

Received August 24, 1993

\begin{abstract}
Variations of surface hardness of alumina induced by ion implantation were studied by using a dynamic ultramicrohardness tester changing the maximum loads as 2, 20 and $120 \mathrm{gf}$. Implanted ion species and energies were $0.4 \mathrm{MeV} \mathrm{B}^{+}, 0.7 \mathrm{MeV} \mathrm{Si}{ }^{+}$in which $1.3 \mathrm{MeV} \mathrm{Cu}^{+}$, and their projection ranges were almost the same of $0.6 \mu \mathrm{m}$, and $3 \mathrm{MeV}$ of $\mathrm{B}^{2+}, \mathrm{Si}^{2+}$ and $\mathrm{Cu}^{2+}$. The implantation dose was mainly $1 \times 10^{16}$ ions $/ \mathrm{cm}^{2}$. Hardness for the loads of 2 and $20 \mathrm{gf}$ was increased in any implantation. But the change in hardness for $120 \mathrm{gf}$ was negligibly small. Apparent depth profile of the dynamic hardness, which was obtained from the "load-depth" data in indentation, showed clear increase of hardness in the top layer and relatively softer layer beneath of it. The thickness of the harder layer was in-creased with the increase of the implantation energy. Heat treatment $\left(1000^{\circ} \mathrm{C} .1 \mathrm{hr}\right.$, in $\left.\mathrm{Ar}\right)$ made the surface softer generally. Comparing with the unimplanted samples. however, the dynamic hard-ness, especially for the loads of $20 \mathrm{gf}$ was increased. There was a tendency that the heavier ion species and the higher energy implantation showed the larger increase of hardness.
\end{abstract}

\section{1 緒 言}

MeVオーダーの高エネルギーイオン注入による，七う ミックス等の固体材料の硬度, 強度.じん性, 而摩耗性, 耐酸化性等の機械的特性の改善が，表面改質の見地から注 目され、研究が進められている1-3)。しかし、イオン注入 による表面改質は、その改質層の厚みが非常に薄く，その 効果を評価する手法は限られる。ささらに。セラミックスの ような材料自体の機械的特性が大きくばらつくものへの応 用では、試料自体のばらつきとイオン注入による变化をい かに区別し評価するかという問題もある.このため。この 技術への期待は大きいが、なかなか進んでいない。
近年. 極微小荷重預域で荷重を連続的に变化させ, その 時の圧子の押し込み梁さを直接測定する動的微小硬度湘定 が実用化され，イオン注入後の材料表面の評価に利用され 始めた 4-7). しかし，対象牥多くが単結晶（特にサファイ ア）で、焼結体への注入及び評価の研究は少ない4)，そこ で、アルミナ焼結体へのイオン注入による表面硬度の变化 を動的硬度測定により調べた．この際，動的硬度測定にお ける荷重一押し込み深さの連続的な測定から，見かけ上の 硬度の染さ分布を求める方法を提案し.その染さ分布の変 化を、イオン種，エネルギー及び注入量を变えて調べた。 また，注入後の熱処理の影響についても調べた。 
Table 1 Implantation condition and projection range

\begin{tabular}{|c|c|c|c|c|c|c|}
\hline Ion species & $\mathrm{B}^{+}$ & $\mathrm{B}^{2+}$ & $\mathrm{Si}^{+}$ & $\mathrm{Si}^{2+}$ & $\mathrm{Cu}^{+}$ & $\mathrm{Cu}^{2+}$ \\
\hline Energy $(\mathrm{MeV})$ & 0.40 & 3.0 & 0.75 & 3.0 & 1.3 & 3.0 \\
\hline Range ( $\mu \mathrm{s}$ & 0.60 & 2. & 0.61 & 1.5 & 0.56 & 1.2 \\
\hline $\operatorname{Dose}\left(10^{\left.15 / \mathrm{cm}^{2}\right)}\right.$ & 110 & 10 & \begin{tabular}{l|l}
11 & 10
\end{tabular} & 10 & \begin{tabular}{l|l|l}
0.05 & 10 \\
\end{tabular} & 0.05 \\
\hline
\end{tabular}

\section{2 実唋}

イオン注入する試料には鏡面研磨されたホットブレスア ルミナ(ダイジェット工業製. $4 \mathrm{~mm} \times 3 \mathrm{~mm} \times 40 \mathrm{~mm})$ を用いた。 イオン注入には大阪工業技術試踰所のタンデム型イオン加 速器(日新ハイボルテー製)を用いた、注入イオン種とし ては.B.Si,Cuの1荷または2荷の正イオンを、エネルギー は注入イオンの飛程が0.6 と3MeV，注入量は $1 \times 10^{16} \mathrm{ions} / \mathrm{cm}^{2}$ を主とし表面改質とし ては低注入䤚域で行った.イオン注入の条件と注入された イオンの平均飛程の計算値(TRIM90 $\left.{ }^{8}\right)$ )をTable 1に示す. 注 入時試料ホルダーを水冷し温度上昇を抑えたが、3MeVSi ${ }^{2+}$ 注入時には水泠無しの実験（N.C.と略記）も行った.

硬度の溂定は，ビッカース死子を取り付けた動的微小硬 度計（島津㹕作所，DOH-200）を用い。最大荷重及び押し込 み速度を2，20，120gf及び0.27，1.44，1.44gf/secと变え て潰した。そして、最大荷重で30秒間保持した．20,120 gf時には庄痕の大きさから通常のビッカース硬度 (Hv)も求 めた. 測定は1試料について3-5点行い，明らかに平均から 逸脱する测定值を除いて平均し代表値とした。

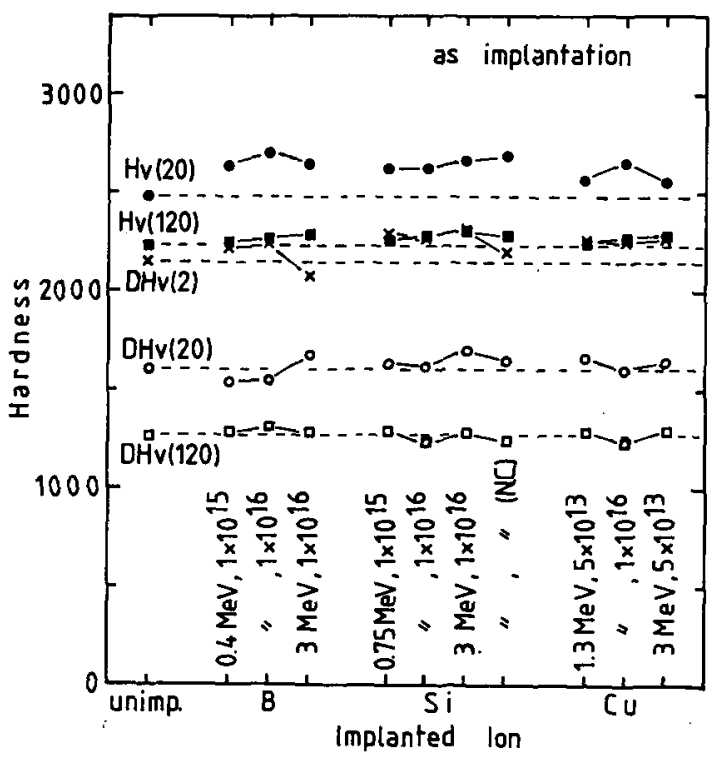

Fig. 1 Vickers hardness (Hv) and dynamic hardness (DHv) of ion implanted alumina. The figures in the parentheses show the maximum loads (gf) in measuring the hardness.
動的硬度 (DHv)の算出には次式を用いた。 $\mathrm{DHv}=\alpha \cdot \mathrm{p} / \mathrm{D}^{2}$

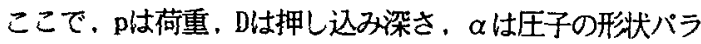
メーターで、この場合. 37.838である.

\section{3 結果と考察}

\section{1 硬度測定結果}

表面硬度の測定結果をFig.1に示す．まず全体に未注入試 料も含めて硬度の荷重依存性が顕著である、高荷重ほど低 硬度を示している，また，同じ荷重でのビッカース硬度は 動的硬度の約 2 倍である、動的硬度は圧子の浸入にともな う弾性変形と塑性变形の和であることを考慮すると，それ らの変形の効果がほぼ同程度であることを示している。

ビッカース硬度を見ると, 荷重20gfの時 $(\mathrm{Hv}$ (20)) 何れの 注入においても未注入に比べて 1 割程度の上昇がある.一 方. 120gf (Hv(120))では僅かな増加しか見られない.これ は極表面のみがイオン注入により硬化していることを示し ている、動的硬度を見ると2gf時(DHv (2)) は增加がみられる が. 20, $120 \mathrm{gf}(\mathrm{DHv}(20), \mathrm{DHv}(120))$ ではほとんど变化して いない，B，Si注入では高エネルギ一注入時にDHv (20)がやや 上界している。イオン種，注入エネルギー，注入量の表面 硬度への影響は，この図では明膫ではない。

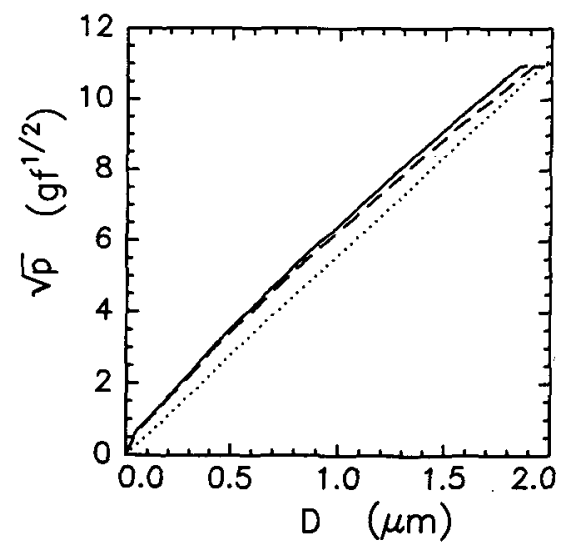

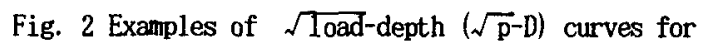
the maximum load of $120 \mathrm{gf}$ to unimplanted alumina (dashed line) and $1.3 \mathrm{MeV} \mathrm{Cu}^{2+}$ implanted alumina at the dose of $5 \times 10^{13}$ ions $/ \mathrm{cm}^{2}$ (solid line). Dotted line shows the slope in evaluation of the dynamic hardness. 


\section{2 見か外上の硬度の深さ分布}

硬度測定の結果は注入 ·未注入試料共に顕著な荷重依存 性を示した. 動的硬度の算出には(1)式を用いたがこれを变 形すると，

$$
\mathrm{DHv}=\alpha \cdot(\sqrt{\mathrm{p}} / \mathrm{D})^{2}
$$

となり，動的硬度は原点と $\sqrt{\mathrm{p}}-\mathrm{D}$ 曲線上の点とを結ぶ直線 の傾き $(\sqrt{\mathrm{p}} / \mathrm{D})$ の2乗に比例することになる．Fig.2はこ の、 $\sqrt{\mathrm{p}}$-D曲線の例を示したものである. イオン注入試料の 方が最大荷重での押し込み染さが小さく，Fig.1にその結果 を示したように、イオン注入により動的硬度が上昇してい ることを示している。

この曲線は，硬度に荷重依存性がない場合，言い換えれ ば(2)式の $\sqrt{\mathrm{p}} / \mathrm{D} か$ 荷重によらず一定の場合には，直線にな る。しかし、イオン注入した試料も未注入の試料も共に。 $\sqrt{\mathrm{p}}$-D曲線は表面側で傾きが大きく，内部に向かうほど楥 やがてなっている.Fig.1に示した動的硬度はFig.2中に点 線て示した，最終的な押し込み深さと最大荷重で決まる点 を通る直線の傾きで評価される，この点線の傾きと，原点 と測定された $\sqrt{\mathrm{p}}-\mathrm{D}$ 曲線上の各点とを結ぶ直線の傾きとを 比較すると，その直線の傾きは。表面側は相対的に大きく （硬度はより高い）,内部は小さい（硬度はより低い）。 特に. 深さ0.05 $\mu$ 以以下の最表面部では，この傾きが非常に 大きくなっており，硬度に換算すると4000あるいはそれ以 上に相当する．この大きな傾きは，最大荷重で30秒間保持 した䏅に圧子がさらにかなりの深さ浸入することを考え合 わせると、試料の変形が圧子の浸入速度に追従し切れてい ないためと考えられる.

通常，見かけ上の動的硬度の深さ分布は，原点とFig.2の 曲線上の各点とを結ぶ直線の傾きによって評価されるが， 変形の遅九によると思われる最表面の超高硬度の影響が表 面に近い点ほど大きくなってしまう。そこで，(2)式中の傾 き $(\sqrt{\mathrm{p}} / \mathrm{D})$ を，曲線上の各点での接線の傾きに置き換える と最表面の影響はほとんど無視でき、より実際に近い見か け上の動的硬度の深さ分布を見積もれる。

Fig.3にこうして見積もった見かけ上の動的硬度の深さ分 布を示す. 実際のデー夕は測定誤差や焼結体自体の不均一 等による非常に細かい変動があるので,ここで示した分布 はかなりの平滑化処理を施したものである、未注入試料で も (点線) 硬度が表面で高くなっているのは，研磨等の機 械加工に伴う残留応力のためと考えられる. イオン注入さ れた試料の硬度分布 (実線) は未注入試料の硬度分布より も高く，イオン注入による硬度の上昇が明暸に示されてい る.特に，極表面の動的硬度の上昇力㗼著である．こ扎は Fig.1の結果と良く対応しており，曲線の接線の傾きと式 (2)から求めた見かけ上の動的硬度分布がイオン注入によっ て生じた硬度变化の良い指標となることを示している。

Fig. 3で $0.4 \mathrm{MeVB}^{+} 1 \times 10^{16}, 0.7 \mathrm{MeVSi}^{+} 1 \times 10^{15}$ 及び $1 \times 10^{16}$ や1.3MeVCu ${ }^{+} 5 \times 10^{13}$ ions $/ \mathrm{cm}^{2}$ 注入では0.4-0.6 $\mu \mathrm{m}$ 付近が相
対的に柔らかい。この深さはTable にに示すように注入した イオンの飛程にほほ対応している. 飛程付近では注入した イオンと格子原子との相互作用が大きく大量の格子欠陷が 生成されると考えられ，この領域の軟化はこの格子欠陷生 成に関連するものであろう。
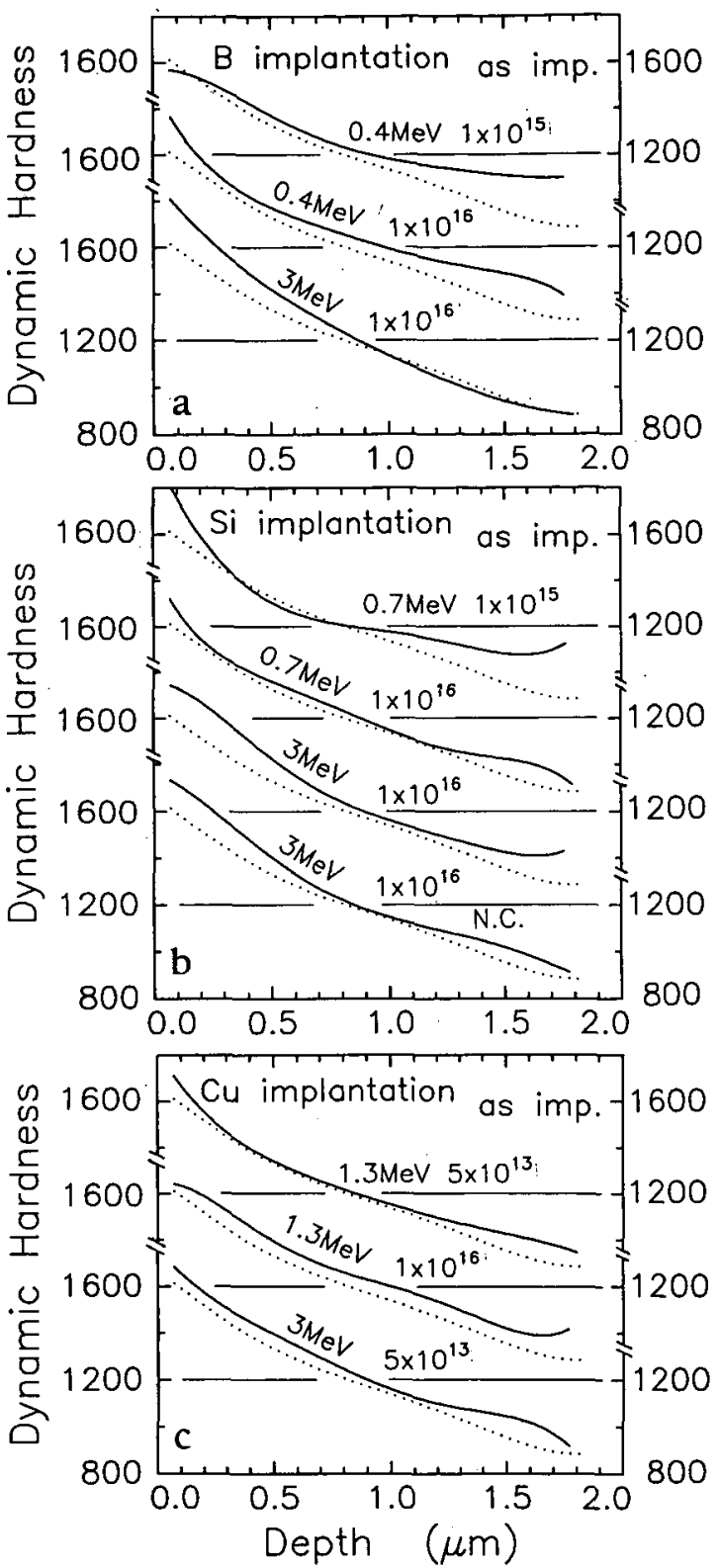

Fig. 3 Apparent depth profiles of dynamic hardness for the maximum load of $120 \mathrm{gf}$. (a) B, (b) Si and (c) $\mathrm{Cu}$ implantation. The figures show the dose of implantation in the unit of ions $/ \mathrm{cm}^{2}$. Dotted lines show the depth profiles for unimplanted alumina. 


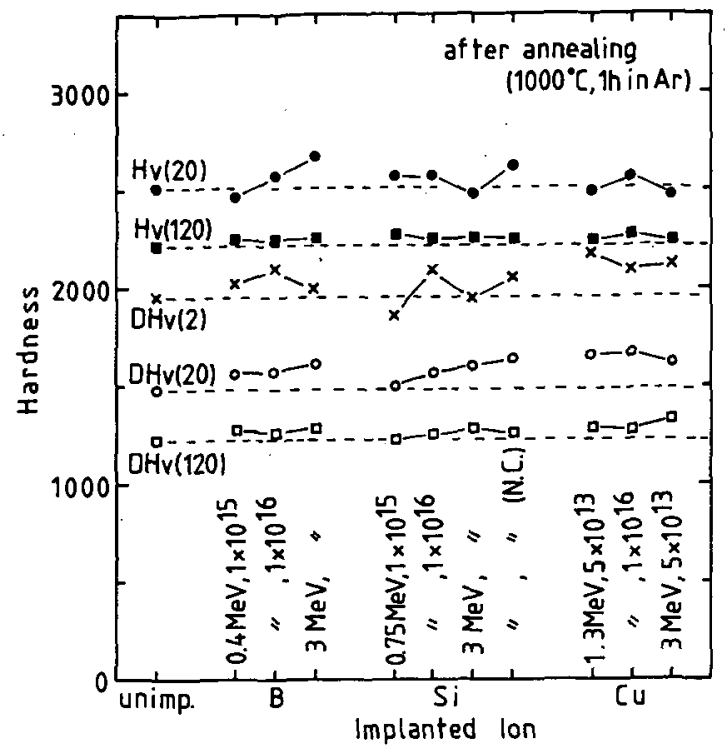

Fig. 4 The same as Fig. 3 except for heat treatment $\left(1000^{\circ} \mathrm{C}, 1 \mathrm{hr}\right.$ in $\left.\mathrm{Ar}\right)$.

B.Si注入で特に硨著であるが、高エネルギー注入の方が 表面の硬化層の厚み办大きくなっている．しかし．極表面 の動的硬度の上昇はむしろ低エネルギー注入の方が大きく なっている，イオン注入によって生じる表面の硬化は，内 部に生じる格子欠宿により発生する表面層の圧縮応力によ ると考えられており 力層が愿くなり，一方，低エネルギーでは圧樎応力の絶対 值が大きくなるためにこのような結果が生じたと解釈でき よう.

\section{3 熱処理}

前節でイオン注入による表面硬化は、生成された格子欠 樎によると述べたが、そうであれば熱処理によって影響を 受けるはずである．Fig.4はFig.1に結果を示した試料をア ルゴン鷅囲気で $1000^{\circ} \mathrm{C} ， 1$ 時間熱処理した後の硬度の測定 結果である．Fig.1と比較すると，末注入試料の，特に低荷 重の動的硬度か爇処理により低下している。これは試料の 切り出し，研磨等の機械加工による残留応力に起因する表 面硬化か淕热処理により除かれたためと思われる。

イオン注入した試料のビッカース硬度は，Hv(20)が顕著 に低下しほぼ末注入と同じになった．Hv (120)はほとんど変 化がない，熱処理による欠陷の回復が硬度の低下を招いた と思われる。一方，動的硬度に関しては，未注入試料と同 様に低下がみられるが，末注入試料との相対的な硬度は。 特にDHv(20)で顕著なように，上昇している．この上昇はB， Si，Cuの順に增加しており，また高エネルギ一注入でより大 きくなる傾向がある.ビッカース硬度は差があまりなく， 動的硬度が上昇しているということは。塑性变形に関して
は差はないが, 弾性変形に関して何らかの違いがあること を示唆するものである。このことは，熱処理により欠宿が どの様に回復するか. また. 注入したイオンがどの様な形 で存在しているかにも大きく関連し，今後の興味深い課題 である.

熱処理に関連して，イオン注入による材料表面改質にお いて注入時の試料温度が大きく影響することが知られてい るが，今回の実験では水冷の有無による温度差は高々数10 ${ }^{\circ} \mathrm{C} て ゙ ，$ 硬度の変化には顕著な差は見られなかった。

熱処理後の見かけ上の動的硬度の梁さ分布は, 極表面層 で動的硬度が末注入よりも上昇しているが，内部はほとん ど变わらないといら結果が, 何れの注入条件でも得られて おり，Fig.4の結果と良く対俯している.

\section{4 まとめ}

アルミナ表面の硬度がイオン注入によってどの様に変化 するかを，最大荷重を2，20，120gfと変えながら動的微小 硬度計によって調べた。イオン注入によって，何れのイオ ン種でも極表面（荷重2，20gf時）の硬度が上昇した. しか し. 最大荷重が120gfでは硬度の变化はほとんど見られなか った. 荷重一押し込み染さのデータから求めた見かけ上の 硬度の深さ分布を見ると最表面の硬度の上界か湿著で，そ の下に相対的に硬度の低い層がみられた，表面の硬化層の 罢みは注入エネルギーが大きいと大きくなった. 熱処理に より，硬度は全体的に下がったが，荷重20gf時の動的硬度 を中心に未注入試料より相対的に高くなった.より重いイ オン種, 高エネルギー注入がより硬くなる傾向があった。

\section{文献}

1) T. Hioki, A. Itoh, M. Ohkubo, S. Noda, H. Doi, J. Kawamoto. 0. Kamigaito, J. Mater. Sci.. 21 (1986) 1321.

2) 岩木正哉. 表面. 25 (1987) 676.

3) C. J. McHargue, Nucl. Inst. and Meth., B19/20 (1987) 797.

4) M.E. O'Hern, C. J. McHargue, C.W. White, G.C. Farlow, Nucl. Inst. and Meth., B46 (1990) 171.

5) N. Moncoffre, Nuc1. Inst. and Meth., B59/60 (1991) 1129.

6) M. Bauer, S.M.M. Ramos, B. Canut, J.L. Loubet, L. Romona, L. Gea, Ph. Kapsa, P.Thevenard, Nucl. Inst. and Meth., B65 (1992) 301.

7) W. Ensinger and R. Nowak, Nucl. Inst. and Meth.. B80/81 (1993) 1085.

8) J.F. Ziegler, J.P. Biersack and U. Littmark, "The Stopping and Range of Ions in Solids". Pergamon, New York (1985). 